\title{
Developing an Approach for a Three-Dimensional Hydrogeologic Framework to Find Water in Northern Ghana
}

\author{
Shannon Holt' ${ }^{1}$ Alexandra Lutz ${ }^{1}$, Bansaga Saga ${ }^{2}$, David L. Berger ${ }^{1}$, \\ James M. Thomas' ${ }^{1}$ Braimah Apambire ${ }^{1}$ \\ ${ }^{1}$ Desert Research Institute, Division of Hydrologic Sciences, Reno, USA \\ ${ }^{2}$ Ghana Integrated Water, Sanitation, and Hygiene Program, World Vision Ghana, Savelugu, Ghana \\ Email: ${ }^{*}$ Alexandra.Lutz@dri.edu
}

Received 25 August 2015; accepted 17 October 2015; published 20 October 2015

Copyright (C) 2015 by authors and Scientific Research Publishing Inc.

This work is licensed under the Creative Commons Attribution International License (CC BY).

http://creativecommons.org/licenses/by/4.0/

(c) (i) Open Access

\section{Abstract}

The purpose of this study was to develop an approach for constructing a three-dimensional hydrogeologic framework using borehole driller logs. The ultimate goal is to increase drilling success rates via a better understanding of the regional hydrogeologic framework in northern Ghana. Groundwater development has increased in northern Ghana, but drilling successful boreholes is difficult due to complex geology and limited aquifer characteristic information. An approach was developed to construct a three-dimensional hydrogeologic framework of the basin using 900 borehole logs from World Vision International's Ghana Integrated Water, Sanitation, and Hygiene Project, located in northern Ghana. The study's approach consists of: evaluating potential software programs; collecting borehole drilling logs; data QA/QC; data standardization and normalization; analysis for trends and correlations; and creation of a three-dimensional hydrogeologic framework and two-dimensional cross sections. This approach can be used and adapted by others working to provide groundwater in developing countries.

\section{Keywords}

Groundwater Management, Hydrogeology, Groundwater Resources, Hydrogeologic Framework, Ghana

\footnotetext{
${ }^{*}$ Corresponding author.

How to cite this paper: Holt, S., Lutz, A., Saga, B., Berger, D.L., Thomas, J.M. and Apambire, B. (2015) Developing an Approach for a Three-Dimensional Hydrogeologic Framework to Find Water in Northern Ghana. Open Journal of Modern Hydrology, 5, 105-120. http://dx.doi.org/10.4236/ojmh.2015.54010
} 


\section{Introduction}

This study develops an approach for a three-dimensional (3D) hydrogeologic framework that will contribute to a better understanding of the regional hydrogeological setting in the administrative Northern Region of Ghana, West Africa (Figure 1). Demand for groundwater in the Northern Region is intensifying because of rapidly increasing population, socio-economic development, and unreliable/poor quality surface-water resources. Developing groundwater, however, is not straightforward in the Northern Region; complicated geological features cause difficulties for drilling successful boreholes and low drilling success rates are reported both anecdotally and in the literature [1]. Complicated hydrogeologic features also cause difficulties for describing aquifer characteristics - they are highly spatially variable and often cannot be described in detail due to financial and temporal constraints.

With insufficient hydrogeological information to guide geophysicists and drillers, success rates remain low in particular areas of northern Ghana. In order to improve drilling success rates, a better understanding of regional hydrogeology is needed. The purpose of this study is to develop an approach for constructing a 3D hydrogeologic framework using driller's borehole logs. The ultimate goal is increasing drilling success rates via a better understanding of the regional hydrogeologic framework. In turn, a better understanding of the hydrogeology contributes to sustainable groundwater development and management. This approach can be used and adapted by others working to provide groundwater, as there is a need for regional studies to contribute to management frameworks and trans boundary issues [2].

For over two decades, World Vision International's Ghana Integrated Water, Sanitation, and Hygiene (GI-WASH) Project has been working to provide safe drinking water to populations in rural areas of Ghana. During the past decade, work has focused on the Northern Region for reasons described above. Hundreds of boreholes have been drilled, and driller's logs record the sub-surface hydrogeological information at each location.

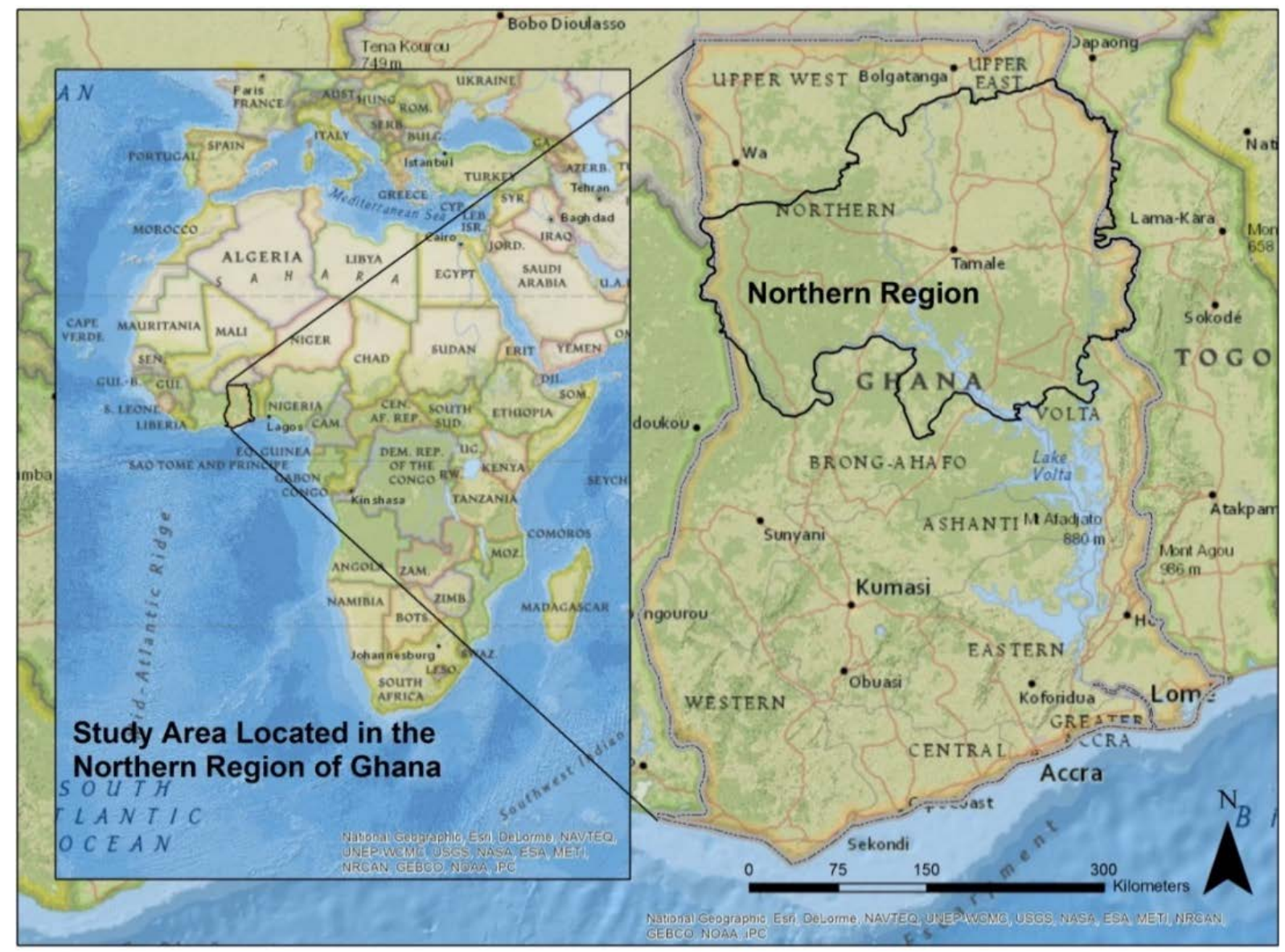

Figure 1. The administrative Northern Region of Ghana. 
Information includes: well location, geology type at depth intervals, total depth, water level, season, and wet or dry borehole. Because these logs contain potentially valuable information, GI-WASH and the Desert Research Institute (DRI) collaborated to analyze these borehole logs in an effort to better understand the regional hydrogeology.

A regional hydrogeologic study typically consists of several steps and is conducted over a number of years. Other approaches taken on the African continent consist of regional groundwater flow models and transboundaryaquifer mapping [2] [3]. The United States Geological Survey (USGS) suggests a methodology consisting of: combining digital elevation models with geologic maps to provide points indicating surface exposures of geologic formations; creation of cross sections from borehole logs to define locations of hydrogeologic units; gridded surface interpolation for each of the hydrogeologic units; a map depicting the trace of faults; interpolation of surface and subsurface data using gridding algorithms; and applying appropriate stratigraphic principles [4]. Gathering of data is an initial and underlying procedure. Since this research focuses on a 3D framework that may contribute to a larger hydrogeological study, a modified approach of combined methods [4]-[6] is taken by GI-WASH and DRI. An outline of the modified approach is: evaluation of appropriate software; data collection; data QA/QC; data standardization; comparisons analysis; and aquifer calculations. More details are given in the approach section. Maps in Figure 1, Figure 2, Figure 5, and Figure 6 were created using ArcGIS ${ }^{\circledR}$ software by Esri. ArcGIS ${ }^{\circledR}$ and ArcMap ${ }^{\mathrm{TM}}$ are the intellectual property of ESRI and are used herein under license. For more information about ESRI ${ }^{\circledR}$ software, please visit www.esri.com.

\section{Study Area Background}

\subsection{Groundwater Development and Management}

Traditionally, surface water has been a primary water source in northern Ghana, but it is no longer viable due to water-borne pathogens, pollution, changes in rainfall patterns, and unavailability during long drought periods [7] [8]. This leads to groundwater development as a cost effective means for supplying rural communities with potable water [9]. Groundwater in Ghana generally has good chemical and microbial quality as compared to surface water, which makes it the preferred choice for safe drinking water [10].

Rural, subsistence family farms describe much of the setting of northern Ghana. The population in the Northern Region makes up approximately $20 \%$ of the total population of Ghana [7] [10], which is about 5 million people based on a 2013 population estimate [11]. Sixty-eight percent of the total population of the Northern Region lives in rural communities. Rural communities are defined as less than 5000 inhabitants [12]. Approximately $70 \%$ of the population relies on subsistence farming as a primary source of income [8]. Across West Africa, food security, droughts, and famine are persistent problems. Groundwater is not only important as a source of potable water, but can also improve the socio-economic status of a community. In sub-Saharan Africa, poverty rose from $42 \%$ in 1981 to $47 \%$ in 2001 , and was mainly attributed to issues of food security. In comparable developing countries in Asia, poverty levels decreased due to the development of groundwater for irrigation purposes, which increased food security [8].

Starting in the 1970s, the government of Ghana commissioned a formal policy that communities with fewer than 500 inhabitants be equipped with hand dug wells, and communities with up to 2000 inhabitants be supplied with boreholes fitted with hand pumps [12]. In 1998, approximately 52\% of the rural population in Ghana depended on boreholes fitted with hand pumps or open wells [7]. In 2012, it was estimated that $81 \%$ of all rural Ghanaians had access to an improved water source [11]; it is noted that this number reflects the country as a whole and not northern Ghana in particular.

\subsection{Study Area Hydrogeology}

The Northern Region of Ghana is within the tropical continental or savannah zone, which experiences a single rainfall season and a long drought period, effectively separating climate into rainy and dry seasons. Rains begin in May, peak between July and August, and taper off by October; the remaining months experience dry, drought-like conditions. In the Savelugu-Nanton District, where the headquarters for GI-WASH is located, mean annual rainfall ranges between 1005 and $1150 \mathrm{~mm}$ [13]. Annual temperature is $18^{\circ} \mathrm{C}$ and humidity ranges from $65 \%$ to $85 \%$ during the rainy season, while temperature is $42^{\circ} \mathrm{C}$ and humidity is $20 \%$ during the dry season [9] [13]. Evapotranspiration rates in northern Ghana average $890 \mathrm{~mm}_{\text {year }}^{-1}$, but depends on season, location, and 
local vegetation [8].

As already discussed, there are complicated geological features in the Northern Region of Ghana. The Voltaian Sedimentary Basin, which underlies significant portions of the region, consists of sandstone, shale, mudstone, sandy and pebbly beds, shown in orange and red on Figure 2 [7] [12] [14]. More geological detail can be found in Yidana et al. [15]. Primary porosity of the Voltaian is limited due to high levels of consolidation and cementation. Thus, preferential groundwater flow paths are along the strike direction of fractures and weathered zones [7] [16] [17].

The fractures and weathered zones result in large variability in hydrogeologic conditions. For example, recharge of groundwater to the Voltaian can range from $2 \%$ to $4 \%$ of the annual rainfall, depending on the location [18]. Hydraulic conductivity has the potential to increase by several orders of magnitude over a short distance of a few meters [17]. Numerical modeling in a small sub-section of the Northern Region suggests hydraulic conductivity values for fractured sandstone range between 0.01 and $3 \mathrm{~m} \cdot \mathrm{day}^{-1}$ and average transmissivity to be $13 \mathrm{~m}^{2} \cdot$ day $^{-1}$ [7]. Across the region, transmissivity is reported to range from 1 to $30 \mathrm{~m}^{2} \cdot$ day $^{-1}$ [19] and more specifically as 0.1 to $52.0 \mathrm{~m}^{2} \cdot \mathrm{day}^{-1}$ and 0.2 to $16.0 \mathrm{~m}^{2} \cdot \mathrm{day}^{-1}$ for sandstone and siltstone/mudstone aquifers, respectively [15].

The highly variable hydrogeologic conditions affect borehole drilling success rates. As much as possible, GI-WASH drillers target fractures and weathered zones of the Voltaian by using geophysical exploration, available information, and anecdotal knowledge. On average, boreholes reach a depth of $48 \mathrm{~m}$ and they rarely exceed $90 \mathrm{~m}$ [8]. In 1996, a 55\% success rate for wet boreholes was reported [1]. Since then, anecdotal reports of drilling success rates vary between $50 \%$ and $80 \%$, with the variance due to localized hydrogeological conditions [20].

Pumping yield can also be highly variable, ranging from 9.8 to $216 \mathrm{~m}^{3} \cdot \mathrm{day}^{-1}\left(6.8\right.$ to $\left.150 \mathrm{~L} \cdot \mathrm{min}^{-1}\right)$ in the Voltaian [12]. In this study, yield is considered to be the maximum rate at which a borehole is pumped without

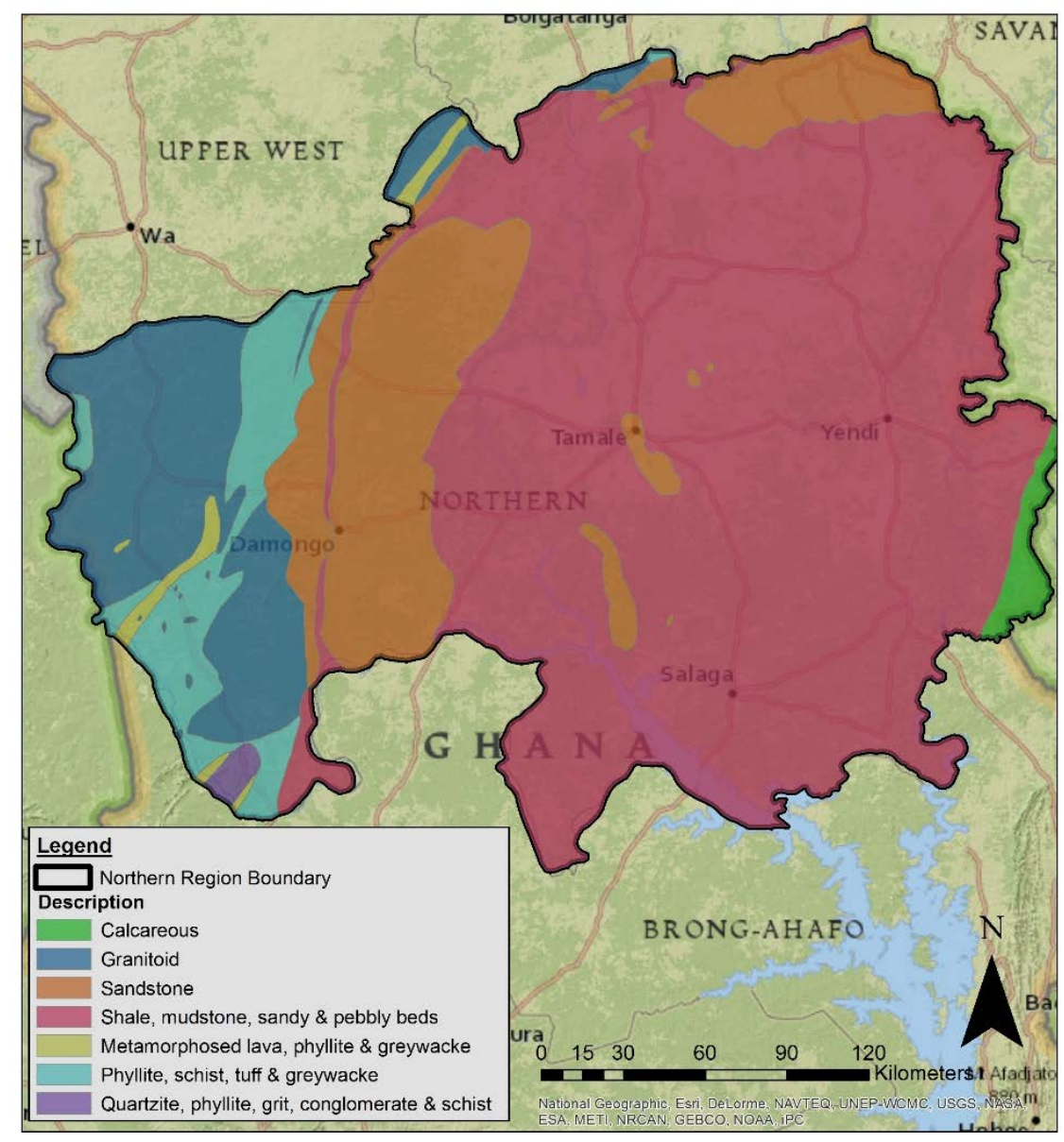

Figure 2. Geologic composition of the Northern Region of Ghana. 
changing the groundwater level during the test [21]. It is noted in this study that GI-WASH pump test methods are modified out of necessity to increase efficiency in the provision of water. Thus, several assumptions are made for representing the aquifer in this study. These assumptions and their limitations are discussed later. At any borehole location, GI-WASH strives for a minimum yield of $18.7 \mathrm{~m}^{3} \cdot \mathrm{day}^{-1}\left(13 \mathrm{~L} \cdot \mathrm{min}^{-1}\right)$ in order to be considered "successful" and develop into a production well to provide adequate water supply to a community of approximately 400 people [22]. In this study, boreholes producing less than the minimum yield are considered dry wells.

\section{Methods and Approach}

The following section describes in greater detail the approach used for constructing a three-dimensional hydrogeologic framework using existing GI-WASH driller's borehole logs. As already described, the approach is modified from several sources [4]-[6]. The modified approach consists of: evaluation of potential software programs; data collection; data QA/QC; data standardization; comparison analysis; aquifer calculation; and construction of cross sections. Figure 3 shows an outline of the approach. It is noted that construction of the cross sections is intended to show that the approach is feasible. Eventually, with more data, we intend to conduct a more rigorous analysis of the hydrogeology.

\subsection{Software Evaluation}

Multiple software packages exist for managing, interpreting, and visualizing hydrogeologic data derived from driller's logs. The software package Rockworks16 [23] was chosen because it meets several requirements including: a user-friendly interface; easy to import and export data; capability to interact with ArcGIS and GoogleEarth; a detailed visual output for 3D maps and 2D cross sections; and the ability to add additional information such as water-quality data. Several limitations, however, became apparent when using this software and the study area's data. These limitations are addressed in the discussion section below.

\subsection{Data Collection}

Data collection consisted of scanning a total of 916 paper borehole drilling logs, recorded from 2002-2010, from GI-WASH during June and July of 2013. Information from the logs was then manually entered into a Microsoft Excel spreadsheet that matched the input parameters for Rockworks16 Borehole Manager Software [23]. Importing an excel sheet directly into the software is the best way to enter a large amount of data quickly. The

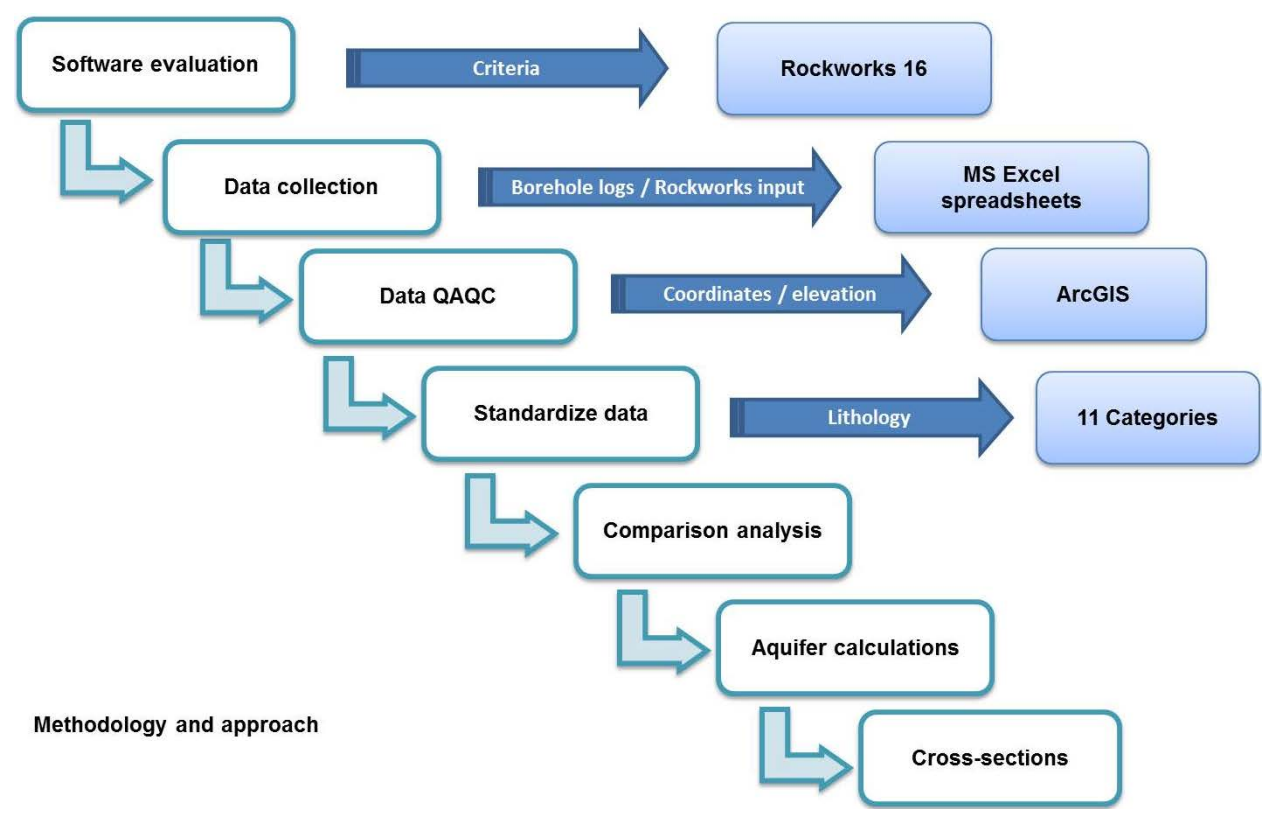

Figure 3. Flow chart of the methodologies and approach taken in this study. 
input parameters include: location; lithology; stratigraphy; I-data, which are numeric values for samples at depth intervals; I-text which is non-numeric information over depth intervals; T-data which are numeric values sampled at depth intervals and time intervals; P-data which are numeric values sampled at single depth points; P-test, which is non-numeric information sampled at a single depth; fractures; water level data; and observed colors down the borehole. These data were input into the Rockworks16 Borehole Manager for each borehole log.

\subsection{Data QA/QC}

Data QA/QC consisted of validating location (coordinates) and elevation information. The location of each well recorded in the borehole log was converted to a shapefile and overlain on the district map of the Northern Region using the ArcMap portion of Esri's ArcGIS. Each borehole was validated to ensure it resided in the correct district reported on the driller's log. When this information was incomplete, it was manually assigned a location in coordination with knowledge from GI-WASH staff and by using Ghana Survey Topography maps and ArcMap. Logs without coordinates, or coordinates that could not be corrected, were removed from the dataset. Missing elevation information was also updated using ArcMap. Digital elevation models were not used for this process since they are only freely available at $90 \mathrm{~m}$ resolution, which is too course for this study. Instead, boreholes were plotted over Ghana Geological Survey elevation contour maps of the country. Missing elevation data were read from the contour map. In cases where the borehole did not place on a contour line, the closest contour line's elevation was used. In areas where multiple known elevations were reported, an average was taken.

Upon completion of QA/QC, 879 of the 916 borehole logs were considered to have accurate coordinates and elevations. Assessing coordinate locations and elevation data was the only metric put into place to evaluate the quality of borehole logs before input into RockWorks16. Detailed information varied between logs, but due to the large study area it was decided that as many logs as possible be used to create cross sections in RockWork16 to minimize the interpolation of the regional hydrogeologic framework. Limitations due to interpolation processes are discussed later. Borehole location and elevation are critical for RockWorks16, as the software cannot manage borehole data lacking this information.

\subsection{Data Standardization}

Data standardization took place during data entry. Information from the borehole logs was entered into Microsoft Excel spreadsheets based on input parameters for the Borehole Manager RockWorks16 software and modified methodology [6] [24]. Diverse expertise of the drilling crews can result in variability of the level of detail described for soils and lithology formations, and the possibility of several different descriptions given for a single unit [24]. A standardization process developed by Ross et al. [5] groups attributes with similar lithology and Russell et al. [6] refined the methodology by rationalizing material descriptions to a limited number of groups that capture their main characteristics. In the rationalization process, descriptions that appear infrequently are removed or re-characterized, combination descriptions are simplified, and the remaining descriptions are reassigned to the appropriate groups. Because Russell et al. [6] used similar drilling methodology as performed in northern Ghana, methodology for standardizing lithology characteristics recorded by GI-WASH followed his example. In the case where descriptions are ambiguous, consultation with the drillers or a literature review took place to correctly characterize the description.

When reviewing the 879 GI-WASH borehole logs as per the methodology described [6] [24], eleven groups emerged (Table 1). A literature review indicated that groundwater is most commonly found in fractures, therefore, lithology categories were focused around fracture characteristics as a dominant attribute. A fractured lithology

\begin{tabular}{llll}
\multicolumn{3}{l}{ Table 1 Eleven dominant lithology types developed for this study. } \\
\hline 1 & Topsoil & & \\
2 & Sandstone & 7 & Fractured Sandstone \\
3 & Mudstone & 8 & Fractured Mudstone \\
4 & Siltstone & 9 & Fractured Siltstone \\
5 & Shale & 10 & Fractured Shale \\
6 & Granite & 11 & Fractured Granite \\
\hline
\end{tabular}


was determined by the borehole log's description as either moderately or highly fractured. Slightly or not fractured were grouped into non-fractured lithologies. Sandstone, siltstone, mudstone, and shale were prevalent lithologies, which agrees with descriptions reported in the literature for the Voltaian [12] [14]. A relatively small percentage of borehole logs that describe areas of granite and other minerals found in granite (about 7\%) were grouped into a single granite category.

In addition to location and lithology types, attributes from the logs also entered into the spreadsheets included: dominant lithology at depth intervals in the borehole; stratigraphic intervals such as confining layers and aquifer intervals; flow rate at intervals and final flow rate (yield); static and dynamic water levels; dry well; and well construction. The dominant lithology represented at the aquifer interval was recorded for each log. The aquifer interval refers to the interval between the depth to water and the final depth of the borehole. Depth to water is recorded on each log during the borehole drilling process. In all cases where the borehole intersects water during the drilling process the yield is measured at depth intervals from the first depth to water recording to the end of the borehole. If the aquifer interval spanned multiple lithology descriptions the most frequent lithologic unit and most frequent degree of fracturing was assigned as the dominant lithology. The dominant lithology for the aquifer interval was then used for comparison analysis. Of the 879 reported boreholes with logs, 368 were considered to be wet and were developed as water supply wells.

\subsection{Comparison Analysis}

Comparison analysis was done to evaluate well yield and aquifer lithology in order to begin to better characterize aquifers in the study area and determine favorable lithologic units for developing groundwater. For this comparison to be valid, each borehole must be constructed with the same well casing diameter and the method of measuring yield must be standardized. Fortunately, GI-WASH boreholes have the same well casing diameters and standardized yield measurements. During the drilling process, depth to water is recorded and yield is measured until the final depth of the borehole is reached, and a final yield is reported.

Yield values ranged from 7.2 to $424 \mathrm{~m}^{3} \cdot \mathrm{day}^{-1}\left(5\right.$ to $\left.295 \mathrm{~L} \cdot \mathrm{min}^{-1}\right)$ with a median of $33.1 \mathrm{~m}^{3} \cdot \mathrm{day}^{-1}\left(22 \mathrm{~L} \cdot \mathrm{min}^{-1}\right)$. For this study, "aquifer interval length" was used to normalize the yield for each well, for easier visualization of the data. The average length of the aquifer penetrated by the boreholes is $13 \mathrm{~m}$. Minimum and maximum lengths are 3 and $46 \mathrm{~m}$, respectively. Yield was divided by the aquifer interval length to obtain a yield value per meter of aquifer interval.

Boxplots were employed to evaluate yield and lithology. A boxplot graphically displays the distribution of the data set [23]. In summary, the mid line is the median of the data and the upper and lower quartile lines display where the bulk of the data points reside. The upper quartile line indicates $75 \%$ of the data is equal to or less than this line, and the lower quartile line indicates $25 \%$ of the data is equal to or less than this line. The whiskers or straight lines extending from the box represent the maximum and minimum data values, while asterisks display outliers.

Figure 4 shows the distribution of fractured and non-fractured lithologies (x-axis) and value of normalized yield per meter of aquifer interval (y-axis). Comparison of the distribution of fractured versus non-fractured lithologies shows that fractured granite, sandstone, and siltstone have higher upper quartile lines, indicating $75 \%$ of the data points have a higher yield than that of their non-fractured counterparts. These fractured lithologies also have comparatively higher median values. The approximate median value for all three lithology types is 5 $\mathrm{m}^{3} \cdot \mathrm{day}^{-1}$ and the upper quarter line values are about $15 \mathrm{~m}^{3} \cdot \mathrm{day}^{-1}$. Two wells had final yield values of 1242 (863 $\left.\mathrm{L} \cdot \mathrm{min}^{-1}\right)$ and $1080 \mathrm{~m}^{3} \cdot \mathrm{day}^{-1}\left(750 \mathrm{~L} \cdot \mathrm{min}^{-1}\right)$, which were categorized as outliers and removed from the dataset for easier visualization of the data. Three wells had yield values between 100 and $200 \mathrm{~m}^{3} \cdot \mathrm{day}^{-1}$, and these were removed from the plot for easier visualization of the data. Of the 368 wet wells, 299 were drilled into fractures, which implies that $81 \%$ of the wet wells have screened intervals in a fractured rock.

\subsection{Aquifer Calculations}

Aquifer calculations were conducted on the 140 of the 879 boreholes with logs that contained aquifer test data and static and pumping water levels needed to calculate specific capacity and transmissivity. Most pumping tests were performed for two hours, but a few were between one and six hours. In instances where no time duration between the static and pumping water level was recorded a time period of two hours was assumed, which is the standard protocol for the drilling crews [22]. 


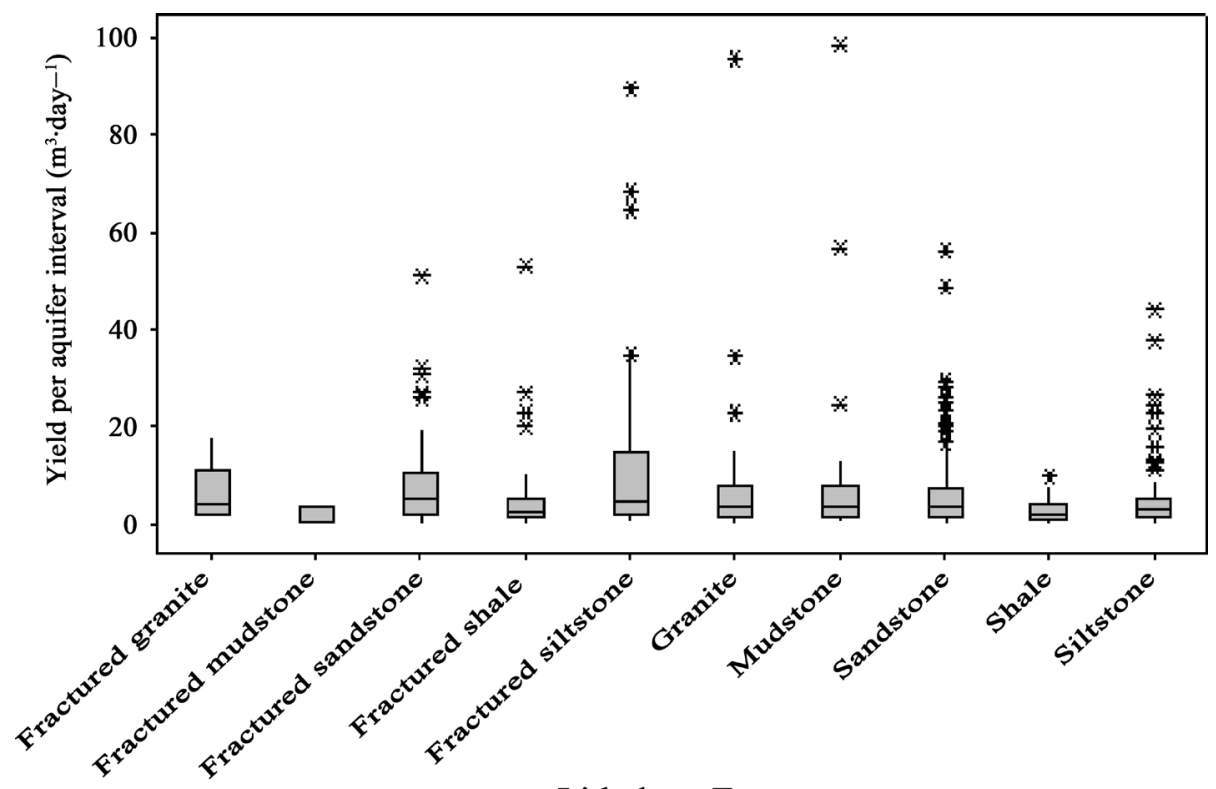

Lithology Type

Figure 4. Boxplot distribution of fractured and non-fractured lithologies (x-axis) and values of normalized yield per meter of aquifer interval (y-axis).

Transmissivity was calculated using an equation developed by Yidana et al. for Voltaian aquifers [16]:

$$
T=0.752 S C^{1.076}
$$

where: $T$ is the transmissivity calculated in $\mathrm{m}^{2} \cdot$ day $^{-1}$ and $S C$ is the specific capacity. Transmissivity ranges from less than 1 to $1753 \mathrm{~m}^{2} \cdot$ day $^{-1}$, averaging $28 \mathrm{~m}^{2} \cdot$ day $^{-1}$ and a median value of $2.2 \mathrm{~m}^{2} \cdot$ day $^{-1}$. Seven wells with yields exceeding $300 \mathrm{~L} \cdot \mathrm{min}^{-1}$ were removed from the dataset, as yields exceeding this value are possible errors, resulting in an average transmissivity value of $12 \mathrm{~m}^{2} \cdot \mathrm{day}^{-1}$, median value of $1.8 \mathrm{~m}^{2} \cdot \mathrm{day}^{-1}$.

\subsection{Cross Section Development}

The interpolation technique used in RockWorks16 is lithoblending, which horizontally extends the lithology from the control point (borehole log) until it hits a voxel (a three-dimensional volumetric cell) that has already been assigned a value as another control point (another borehole log). A more detailed description of lithoblending can be found in the RockWorks16 Training Manual [23]. In short, lithoblending must interpolate outliers or large gaps in lithology that exist throughout the domain area in order to easily map two-dimensional cross-sections. The 3D model was generated from the eleven lithology categories and interpolated across the domain space (Figure 5). The output dimensions of the interpolated solid model match those of the input boreholes, and a vertical exaggeration of 100 is applied to more easily view the model.

Smaller two-dimensional cross sections were developed from the 3D model to provide more sub-surface detail. First, the entire domain space is cut in four east-to-west directions and four north-to-south directions (Figure 6, upper). Then, smaller cross sections were cut in areas where large clusters of unsuccessful (dry or low-yielding) wells occur, or in areas where high yielding wells occur (Figure 6, lower). All water levels were plotted on the 2D cross sections using the Water Level Table in RockWorks16. Water levels are shown as a thick blue horizontal lines and should not be interpreted as the aquifer or the depth of the aquifer; rather, it is an interpreted aquifer profile, the limitations of which are discussed later. In this study, the upper part of the thick blue water level line represents depth to water during drilling, while the lower line represents the well bottom. Limited spatial and temporal data necessitated the assumption that the aquifer reported in the drilling logs is continuous and confined and depth to water recorded during the drilling process was at the same time of year for each well to eliminate variation in water table levels from the wet and dry season.

Figure 7 shows the four west to east cross sections developed using borehole logs near each profile line. Cross Section 4 has the most interpolation from the west-to-east direction due to limited and poorly spaced bo- 
reholes. Figure 8 shows the four north-to-south cross sections developed using borehole logs near each profile line. The majority of boreholes are located in the northern portion of the study domain compared to sparse boreholes in the southern portion of the domain. For this reason, a large amount of error and interpolation is expected on the southern portions of the north-south cross sections.

Figure 9 displays cross sections in areas where clusters of unsuccessful dry or higher yielding wells are found. Cross sections A, B, C, E, F, I, M, and N are drawn in areas where significantly more unsuccessful (dry or low

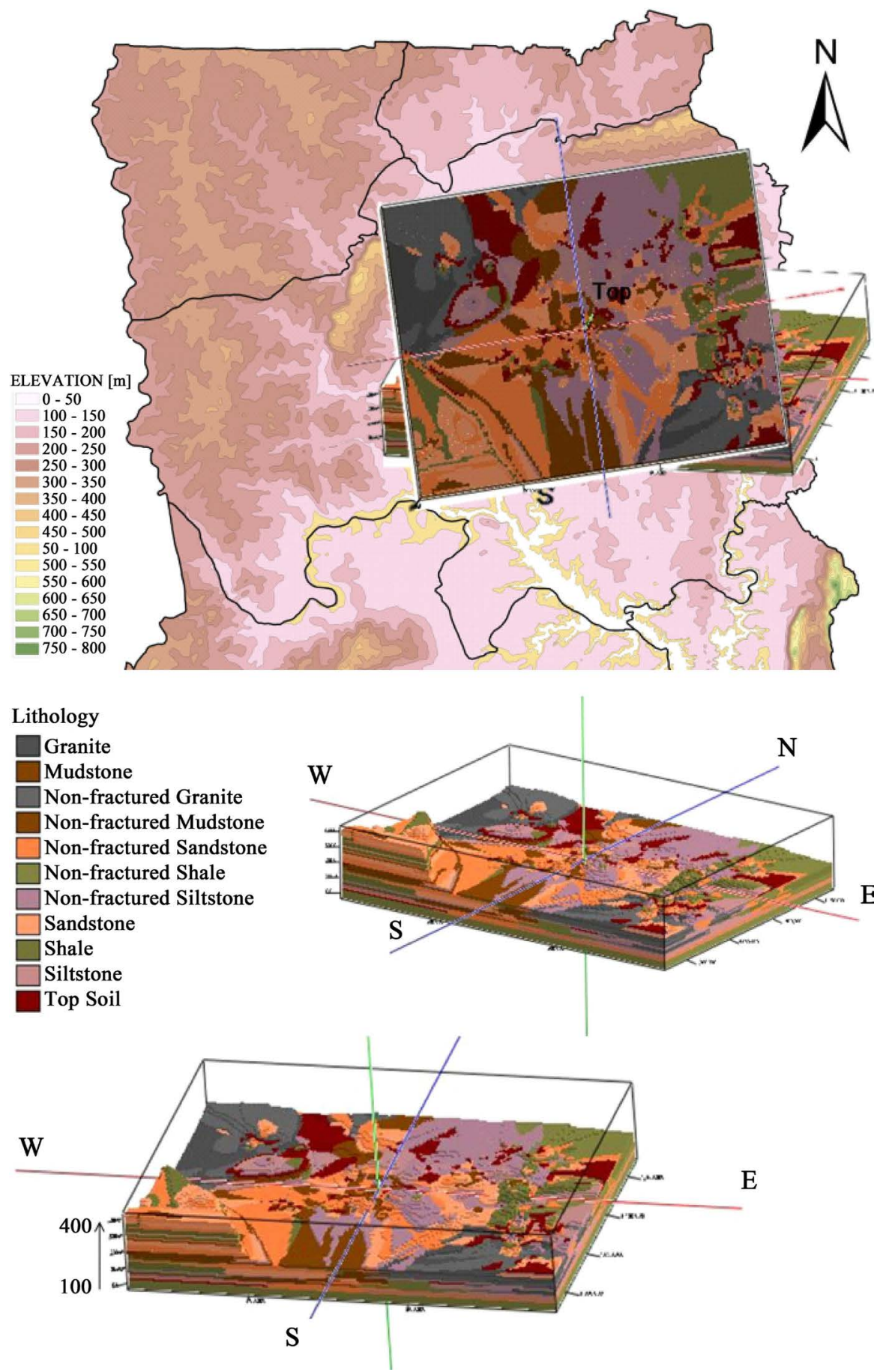

Figure 5. Left: three-dimensional model generated from lithology categories interpolated across domain space and overlaid on map of Ghana. Right: model and cross-section from southerly and south-easterly directions. 


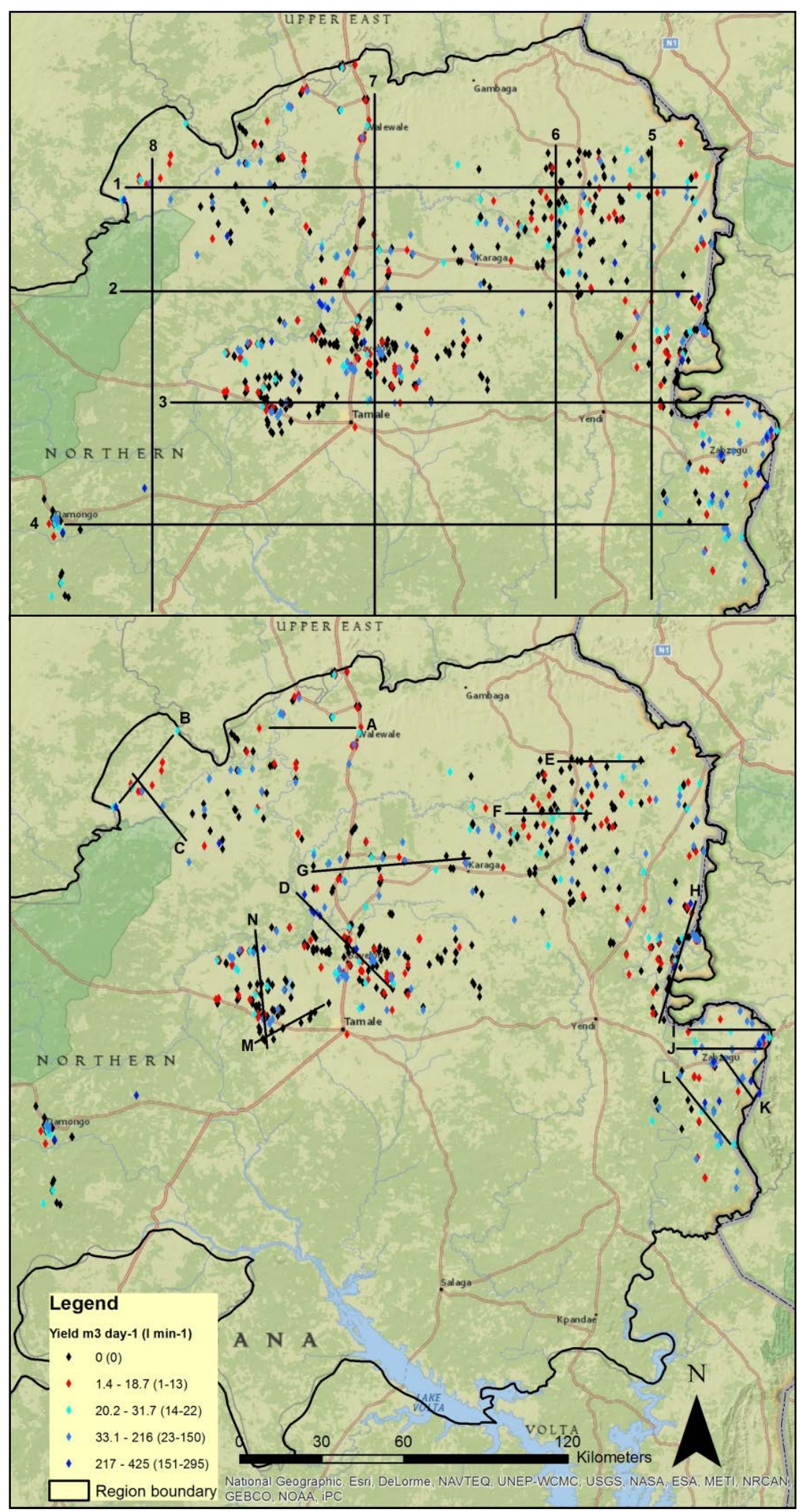

Figure 6. Upper: the domain is cut into four east-to-west $(1-4)$ and north-to-south (5 - 8) directional cross sections. Lower: cross sections A, B, C, E, F, I, M, and N are drawn in areas where larger groups of unsuccessful (dry or low yielding) wells were drilled. Cross sections D, G, H, and J are drawn in areas where successful (higher yielding) wells were drilled. 

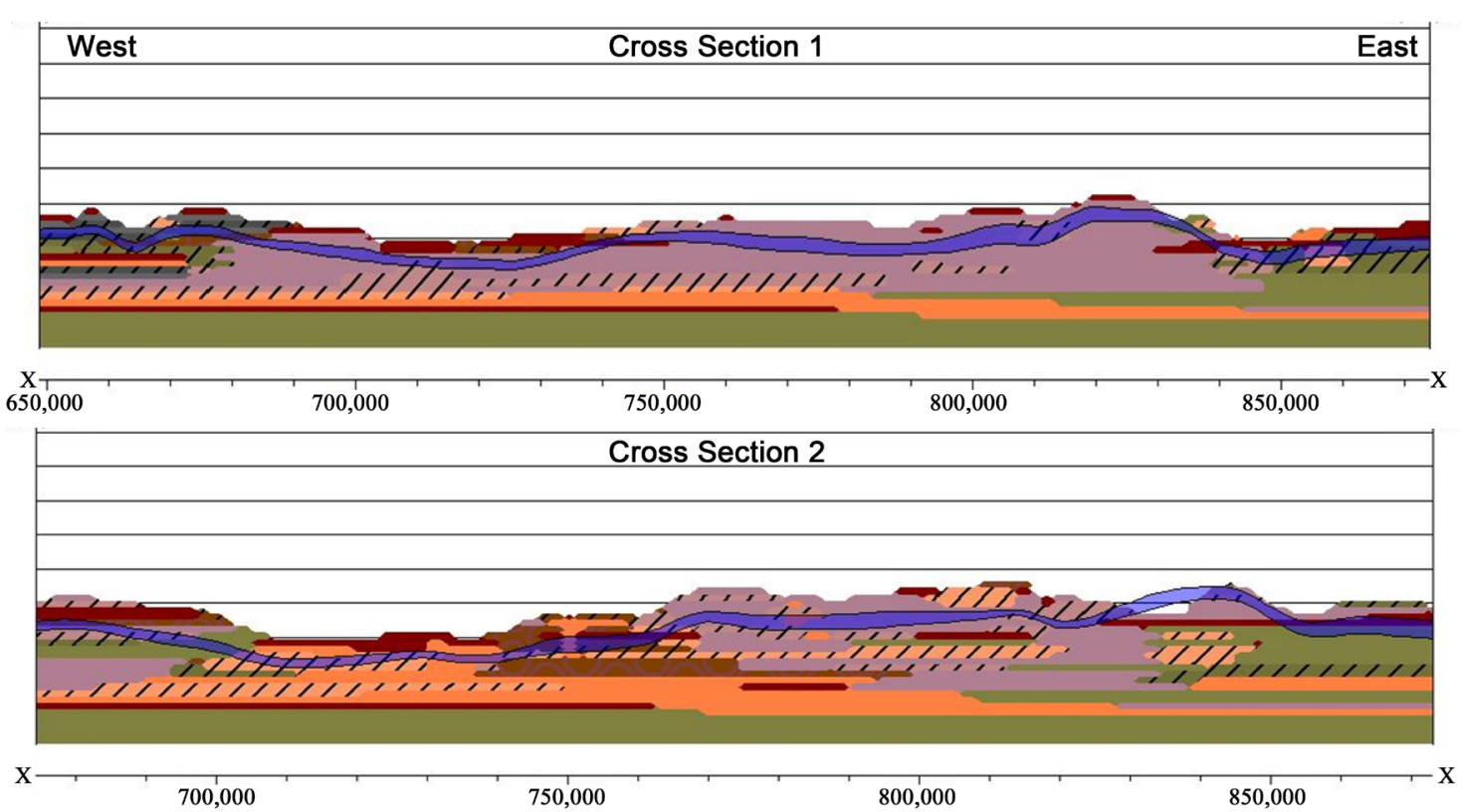
X
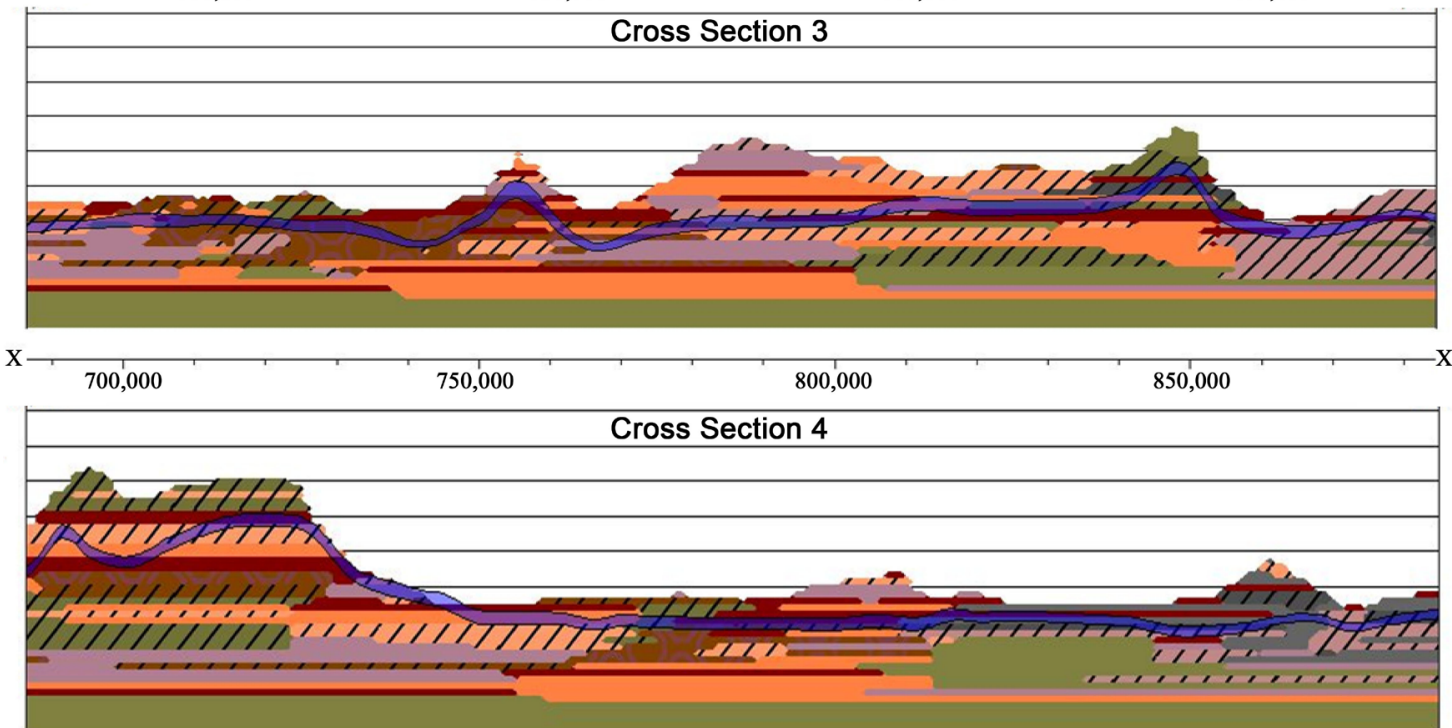

\begin{tabular}{|c|c|c|c|c|}
\hline \multirow[t]{13}{*}{650,000} & \multirow[t]{13}{*}{700,000} & \multirow[t]{13}{*}{750,000} & \multirow[t]{13}{*}{800,000} & 850,000 \\
\hline & & & & Lithology \\
\hline & & & & Top Soil \\
\hline & & & & Non-fractured Sandstone \\
\hline & & & & Non-fractured Mudstone \\
\hline & & & & Non-fractured Siltstone \\
\hline & & & & Non-fractured Shale \\
\hline & & & & Non-fractured Granite \\
\hline & & & & $\square 】$ Sandstone \\
\hline & & & & Z】 Mudstone \\
\hline & & & & Z/D Siltone \\
\hline & & & & $\square \backslash \triangle$ Shale \\
\hline & & & & $\varnothing / \triangle$ Granite \\
\hline
\end{tabular}

Figure 7. Four cross section profiles drawn in the west-to-east direction domain for an overall horizontal representation of the study domain. The blue line running through the profile is the interpolated aquifer profile. The $\mathrm{x}$-axis is the distance along the lithology profile in meters. The vertical tick marks on the y-axis are elevation reported as meters above sea level [23]. 

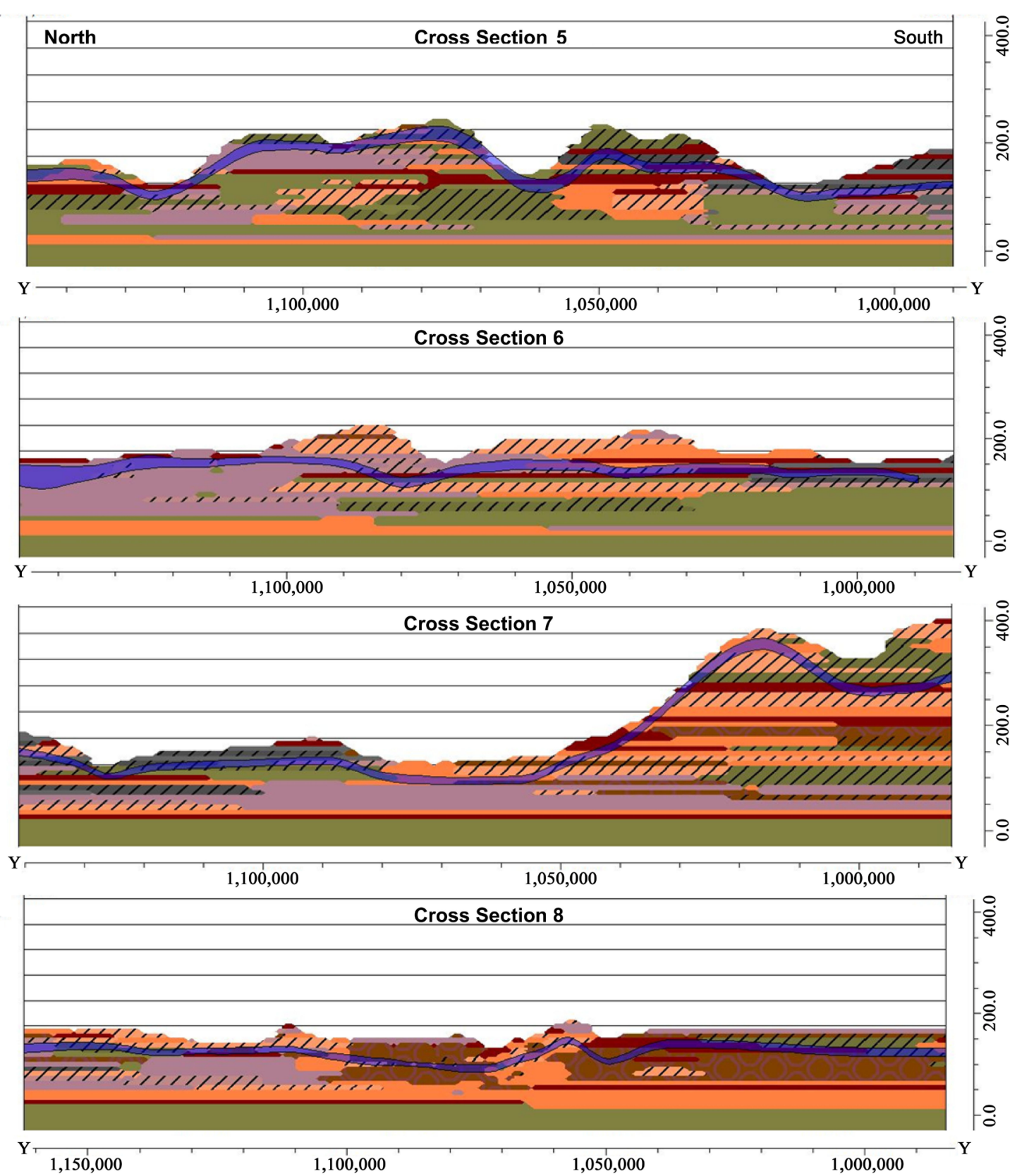

\begin{tabular}{|c|c|}
\hline & Lithology \\
\hline & Top Soil \\
\hline & Non-fractured Sandstone \\
\hline & Non-fractured Mudstone \\
\hline & Non-fractured Siltstone \\
\hline & Non-fractured Shale \\
\hline & Non-fractured Granite \\
\hline VI & Sandstone \\
\hline EZ & Mudstone \\
\hline ZZ & Siltone \\
\hline$\angle Z$ & Shale \\
\hline$\angle Z$ & Granite \\
\hline
\end{tabular}

Figure 8. Four cross section profiles drawn in the north-to-south direction domain for an overall vertical representation of the study domain. The blue line running through the profile is the interpolated aquifer profile. The $y$-axis is the distance along the lithology profile in meters. The vertical tick marks on the y-axis are elevation reported as meters above sea level [23]. 


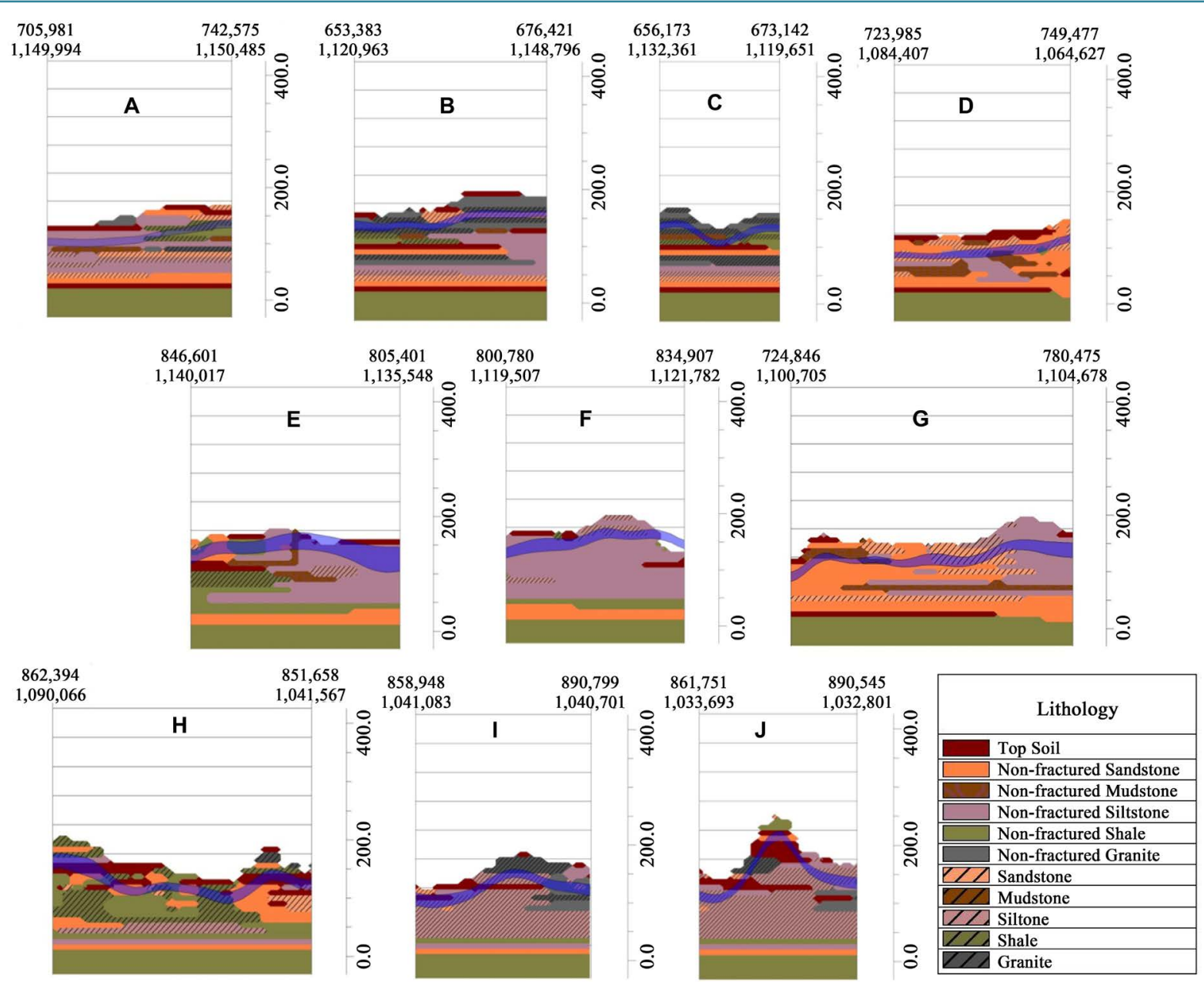

Figure 9. Smaller cross section profiles that represent areas of interest including clusters of dry, low yielding, and clusters of wet, higher yielding, wells. The blue line running through the profile is the interpolated aquifer profile. The coordinates in the upper left and right corners of the profiles are reported in UTM Zone 30, x-easting and y-northing. The vertical tick marks on the $\mathrm{y}$-axis is the elevation reported in meters above sea level [23].

yielding) than successful (higher yielding) wells were drilled. Cross sections D, G, H, and Jare drawn in areas where significantly more successful (higher yielding) wells were drilled. Higher yielding wells are found in the Zabzugu-Tatale district located along the eastern border of Ghana. These cross sections, along with spatial distributions visually displayed in any GIS mapping software, can provide insight into areas of preferential drilling. Limitations of the assumptions made above and potential misrepresentation in the $2 \mathrm{D}$ cross sections will be reviewed in the following section.

\section{Discussion}

During the data standardization step, it was noted that 368 of the 879 boreholes with well logs were developed into wet wells. This is a $42 \%$ success rate, as compared with the $55 \%$ success rate reported by Sander et al. [1]. The data used to calculate a 55\% success rate, however, are not known. The borehole logs used in this study span from 2002 to 2010 and do not represent every borehole drilled by GI-WASH in northern areas, therefore, the $42 \%$ success rate may not be representative of the overall drilling success rate.

The average transmissivity value of $28 \mathrm{~m}^{2} \cdot \mathrm{day}^{-1}$ calculated in this study is within the higher range of transmissivity values reported in the literature. It is possible that several larger values are over-representing the average in this study. Removing seven wells with yields exceeding $300 \mathrm{~L} \cdot \mathrm{min}^{-1}$ results in an average transmissivity value of $12 \mathrm{~m}^{2} \cdot \mathrm{day}^{-1}$, which is well within the reported regional range of 1 to $30 \mathrm{~m}^{2} \cdot \mathrm{day}^{-1}$ [15] and agrees with the $13 \mathrm{~m}^{2}$. day ${ }^{-1}$ generated from the numerical model [7]. Grouping the study's remaining wells into sandstone 
and siltstone/mudstone gives average transmissivity values of 21 and $4.3 \mathrm{~m}^{2} \cdot$ day $^{-1}$, respectively. These values are also well within the reported ranges of 0.1 to $52.0 \mathrm{~m}^{2} \cdot$ day $^{-1}$ for sandstone aquifers and 0.2 to $16.0 \mathrm{~m}^{2} \cdot$ day $^{-1}$ for siltstone/mudstone aquifers.

The boxplot figures of lithology and yield reveal higher median and upper quartile values for fractured sandstone, siltstone, and granite and non-fractured granite, suggesting these lithology types are more favorable for producing higher well yields. This statement is consistent with anecdotal knowledge and the literature that indicate fractured sandstone areas are more favorable for groundwater development. The Voltaian Sedimentary Basin is approximately 3000 to $4000 \mathrm{~m}$ thick and the average depth of each borehole is approximately $48 \mathrm{~m}$ [8]. Thus, a detailed representation of the entire basin formation is not reasonable in these relatively shallow cross sections due to limited data with depth. In order to better characterize the basin and make decisions based on the preferential depth to drill, experimental boreholes drilled more deeply would be necessary.

\section{Limitations}

Several limitations are apparent when using the Rockworks software with the study area's data. First is the limitation of scale. For this project the study area spans the majority of the Northern Region of Ghana but only 879 borehole logs available for this large region and these boreholes are generally clustered in small areas. When including all borehole locations in the 3D map and 2D cross sections, wells appear to be on top of each other and are illegible. This issue may be eliminated by decreasing the size of the study area or dividing the area into smaller areas for plotting purposes, however for this particular project that was not an option available for the larger scale analysis.

The next limitation is the spatial distribution of data and the interpolation method. Boreholes are clustered in certain areas and scattered in other areas throughout the domain space. In cases where boreholes are clustered, relatively less interpolation occurs across the sub-surface lithology. Conversely, where boreholes are scattered, relatively more interpolation occurs across the sub-surface lithology. This assumes sub-surface lithological conditions to be unchanging across long distances, such as Cross Section 4 (Figure 7), which is about $200 \mathrm{~km}$. It is also a limitation that the 2D cross sections are developed from the 3D interpolated map, instead of going through a separate interpolation process at the smaller cross section scale. This issue may be eliminated by decreasing the size of the study area, but for the purpose of this project that was not an option.

Another limitation is that depth to water in each borehole is plotted using the aquifer profile for each cross section. Water levels are shown as a thick blue horizontal lines and should not be interpreted as the aquifer or the depth of the aquifer; rather, it is an interpreted aquifer profile. This displays a general thickness and location of the aquifer that each well is completed in. As already discussed, several assumptions are made when representing the aquifer in this manner. The first is that there is one confined and continuous aquifer throughout the basin. In some cases, boreholes are not drilled into fractures and yet yield water. Based on this observation we do not rule out the assumption that a non-continuous or confined aquifer exists. The second assumption is that all boreholes are drilled in the same season. Large variation in water table depth is present in this area due to heavy monsoonal rains followed by a long drought period [21] [24]. Some wells were drilled during times of high water table levels and others in the dry season when the water table has dropped; seasonal variation in water table level is not represented in this study and should be examined more closely in future work.

Finally, the aquifer profile has several limitations in the visual output and may compromise the accuracy of aquifer locations. The depth to water is interpolated across the lithology profile and connected to the next depth to water profile in the closest well. In some cases, the aquifer appears to be above ground since the data set includes dry wells and the aquifer profile may be connecting to the next wet well at a significant distance away. The 2D lithology and aquifer profiles are constructed from a 3D map, so the swath from which the 2D profile is created may consist of data above or below the profile line giving the illusion that the aquifer profile is above ground. This issue may be eliminated by decreasing the size of the study area, but for the purpose of this project that was not an option. Future work should focus on smaller areas of the region.

\section{Conclusions}

The purpose of this study was to develop an approach for constructing a three-dimensional hydrogeologic framework using existing borehole driller's logs. A modified approach to develop a three-dimensional hydrogeologic framework was developed by GI-WASH and DRI in combination with several methodologies [4]-[6]. 
The approach developed in this study consists of: evaluation of appropriate software; data collection; data QA/QC; data standardization; comparisons analysis; and aquifer characteristic calculations.

Rockworks16 was chosen as the software program to develop a three-dimensional hydrogeologic framework for the study area. The program used information from World Vision's northern Ghana GI-WASH driller's logs as input to develop a 3D hydrogeologic framework for the study area. Some limitations of this approach include scale, spatial distribution of data and interpolation of these data, and location and seasonality of the depth to the water table. Data collection shows the importance of detailed information captured in the driller's log and transcription of this information to an electronic spreadsheet format. Data QAQC indicates that not all driller's logs contain accurate location and elevation information, so adjustments were required. Discussion is taking place between DRI and GI-WASH as to altering the format of the driller's logs to capture more detailed information whilst maintaining efficient field operations.

The standardization, comparison analysis, and aquifer characteristics calculations begin to reveal more information as to the local hydrogeology, especially with respect to well yield, transmissivity, and identifying more favorable lithologies to target for shallow groundwater development. This information, along with the 3D framework and 2D cross-sections is anticipated to contribute to a larger regional hydrogeological study in the administrative Northern Region of Ghana, West Africa. The framework and cross sections are intended to show that the approach is feasible, and make a case for compiling more data. Eventually, with more data, we intend to conduct a more rigorous analysis of the hydrogeology (including geophysics data and lineaments analysis). Ultimately, the results from this study should form the foundation for a more robust study of hydrogeology in this region to ensure sufficient, sustainable groundwater development, and management for all inhabitants in the region.

\section{Acknowledgements}

The authors wish to thank the numerous field staff at World Vision International's Ghana Integrated Water, Sanitation and Hygiene Project and the various communities in which the study is taking place. Funding for the project was provided by the Conrad N. Hilton Foundation. The authors also wish to thank three reviewers for their valuable suggestions and comments.

\section{References}

[1] Sander, P., Chesley, M. and Minor, T. (1996) Groundwater Assessment Using Remote Sensing and GIS in a Rural Groundwater Project in Ghana: Lessons Learned. Hydrogeology Journal, 4, 40-49. http://dx.doi.org/10.1007/s100400050086

[2] Belcher, W., Faunt, C. and D’Agnese, F. (2002) Three-Dimensional Hydrogeologic Framework Model for Use with a Steady-State Numerical Ground-Water Flow Model of the Death Valley Regional Flow System, Nevada and California. Water-Resources Investigations Report 01-4254. USGS.

[3] Ross, M., Parent, M. and Lefebvre, R. (2003) 3D Geologic Framework Models for Regional Hydrogeology and LandUse Management: A Case Study from a Quaternary Basin of Southwestern Quebec, Canada. Hydrogeology Journal, 13, 690-707. http://dx.doi.org/10.1007/s10040-004-0365-X

[4] Russell, H., Brennand, T., Logan, C. and Sharpe, D. (1998) Standardization and Assessment of Geological Descriptions from Water Well Records, Greater Toronto and Oak Ridges Moraine Areas, Southern Ontario. Geological Survey of Canada, Ottawa, 89-102.

[5] Lutz, A., Thomas, J., Pohll, G. and McKay, A. (2007) Groundwater Resource Sustainability in the Nabogo Basin of Ghana. Journal of African Earth Sciences, 49, 61-70. http://dx.doi.org/10.1016/j.jafrearsci.2007.06.004

[6] Akudago, J., Chegbeleh, L., Nishigaki, M. and Nanedo, N. (2009) Estimating the Storage and Maximum Annual Yield of the Aquifer System in Northern Ghana and the Potential for Irrigation. Electronic Journal of the International Association for Environmental Hydrology, 17, 1-13.

[7] Anku, Y.S., Banoeng-Yakubo, B., Asiedu, D.K. and Yidana, S. (2008) Water Quality Analysis of Groundwater in Crystalline Basement Rocks, Northern Ghana. Journal of Environmental Geology, 58, 989-997. http://dx.doi.org/10.1007/s00254-008-1578-4

[8] Obuobie, E., Diekkrueger, B., Agyekum, W. and Agodzo, S. (2012) Groundwater Level Monitoring and Recharge Estimation in the White Volta River Basin of Ghana. Journal of African Earth Sciences, 71-72, 80-86. http://dx.doi.org/10.1016/j.jafrearsci.2012.06.005

[9] World Bank Data. http://data.worldbank.org/country/ghana (accessed on 10 October 2014) 
[10] Dapaah-Siakwan, S. and Gyau-Boakye, P. (2000) Hydrogeologic Framework and Borehole Yields in Ghana. Hydrogeology Journal, 8, 405-416. http://dx.doi.org/10.1007/PL00010976

[11] Tay, C. (2012) Hydrochemistry of Groundwater in Savelugu-Nanton District, Northern Ghana. Journal of Environmental Earth Sciences, 67, 2077-2087. http://dx.doi.org/10.1007/s12665-012-1647-6

[12] Acheampong, S. and Hess, J. (2000) Origin of Shallow Groundwater System in the Southern Voltaian Sedimentary Basin of Ghana: An Isotopic Approach. Journal of Hydrology, 233, 37-53. http://dx.doi.org/10.1016/S0022-1694(00)00221-3

[13] Boadu. F., Gyamfi, J. and Owusu, E. (2005) Case History: Determining Subsurface Fracture Characteristics from Azimuthal Resistivity Surveys: A Case Study at Nsawam, Ghana. Journal of Geophysics, 70, 35-42. http://dx.doi.org/10.1190/1.2073888

[14] Yidana, S., Yiran, G., Sakyi, P., Nude, P. and Banoeng-Yakubo, B. (2011) Groundwater Evolution in the Voltaian Basin, Ghana-An Application of Multivariate Statistical Analysesto Hydrochemical Data. Natural Science, 3, 837-854. http://dx.doi.org/10.4236/ns.2011.310109

[15] Teeuw, R. (1995) Groundwater Exploration Using Remote Sensing and a Low-Cost Geographical Information System. Hydrogeology Journal, 3, 21-30. http://dx.doi.org/10.1007/s100400050057

[16] Yidana, S., Banoeng-Yakubo, B., Aliou, A. and Akabzaa, T. (2012) Groundwater Quality in Some Voltaian and Birimian Aquifers in Northern Ghana-An Application of Multivariate Statistical Methods and Geographic Information Systems. Hydrological Sciences Journal, 57, 1168-1183. http://dx.doi.org/10.1080/02626667.2012.693612

[17] Kwei, C. (1997) Evaluation of Groundwater Potential in the Northern Region of Ghana. Comwasan Consult for Canadian International Development Agency.

[18] Nejoh, J. (2013) GI-WASH, Personal Communication.

[19] Harvey, P. (2004) Borehole Sustainability in Rural Africa: An Analysis of Routine Field Data. In: Godfrey, S., Ed., People-Centred Approaches to Water and Environmental Sanitation. Proceedings of the 30th WEDC International Conference, Vientiane, WEDC, Loughborough, 339-346.

[20] Edusei, S. (2013) GI-WASH, Personal Communication.

[21] RockWorks16 Training Manual (2013) Solid Model Algorithms. RockWare, Golden.

[22] Dumedah, G. and Schuurman, N. (2008) Minimizing the Effects of Inaccurate Sediment Description in Borehole Data Using Rough Sets and Transition Probability. Journal of Geographic Systems, 10, 291-315. http://dx.doi.org/10.1007/s10109-008-0066-4

[23] Helsel, D. and Hirsch, R. (2002) Statistical Methods in Water Resources. USGS, Book 4, Hydrologic Analysis and Interpretation, $524 \mathrm{p}$.

[24] Lutz, A., Minyila, S., Saga, B., Diarra, S., Apambire, B. and Thomas, J. (2015) Fluctuation of Groundwater Levels and Recharge Patterns in Northern Ghana. Climate, 3, 1-15. http://dx.doi.org/10.3390/cli3010001 